\title{
Invasive mechanical ventilation using a bilevel PAP ST device in a healthy swine model
}

\author{
Brian E. Foster ${ }^{1}$ (D) $\cdot$ Montserrat Diaz-Abad ${ }^{2} \cdot$ Arlene J. Hudson $^{3} \cdot$ Peter Bedocs $^{3,4,5} \cdot$ Darius M. Doll $^{6} \cdot$ Steven A. Lopez ${ }^{7}$. \\ John Mares $^{5}$. Justin Hutzler ${ }^{5} \cdot$ Brian D. Robertson $^{8}$
}

Received: 18 June 2020 / Revised: 22 June 2020 / Accepted: 25 June 2020 / Published online: 6 August 2020

(C) This is a U.S. government work and not under copyright protection in the U.S.; foreign copyright protection may apply 2020

\begin{abstract}
Purpose The Coronavirus Disease 2019 (COVID-19) pandemic may cause an acute shortage of ventilators. Standard noninvasive bilevel positive airway pressure devices with spontaneous and timed respirations (bilevel PAP ST) could provide invasive ventilation but evidence on their effectiveness in this capacity is limited. We sought to evaluate the ability of bilevel PAP ST to effect gas exchange via invasive ventilation in a healthy swine model.

Methods Two single limb respiratory circuits with passive filtered exhalation were constructed and evaluated. Next, two bilevel PAP ST devices, designed for sleep laboratory and home use, were tested on an intubated healthy swine model using these circuits. These devices were compared to an anesthesia ventilator.

Results We evaluated respiratory mechanics, minute ventilation, oxygenation, and presence of rebreathing for all of these devices. Both bilevel PAP ST devices were able to control the measured parameters. There were noted differences in performance between the two devices. Despite these differences, both devices provided effective invasive ventilation by controlling minute ventilation and providing adequate oxygenation in the animal model.

Conclusions Commercially available bilevel PAP ST can provide invasive ventilation with a single limb respiratory circuit and inline filters to control oxygenation and ventilation without significant rebreathing in a swine model. Further study is needed to evaluate safety and efficacy in clinical disease models. In the setting of a ventilator shortage during the COVID-19 pandemic, and in other resource-constrained situations, these devices may be considered as an effective alternative means for invasive ventilation.
\end{abstract}

Keywords Coronavirus $\cdot$ Ventilators $\cdot$ Mechanical $\cdot$ Respiratory mechanics $\cdot$ Models $\cdot$ Animal $\cdot$ Continuous positive airway pressure $\cdot$ Bilevel positive airway pressure

\section{Introduction}

In December 2019, a novel viral pathogen, the severe acute respiratory syndrome coronavirus 2 (SARS-CoV-2), was discovered in Wuhan, Hubei province, China, with its disease

Brian E. Foster

Brian.E.Foster7.mil@mail.mil

Brian D. Robertson

Brian.D.Robertson2.mil@mail.mil

1 Department of Medicine, Uniformed Services University of the Health Sciences, Bethesda, MD, USA

2 Department of Medicine, University of Maryland School of Medicine, Baltimore, MD, USA

3 Department of Anesthesiology, Uniformed Services University of the Health Sciences, Bethesda, MD, USA named Coronavirus Disease 2019 (COVID-19) [1, 2]. The COVID-19 global pandemic has rapidly escalated, requiring widespread critical care level management of patients to include mechanical ventilation $[3,4]$. The demand for invasive mechanical ventilation has surpassed the supply of ventilators in many

4 Defense and Veterans Center for Integrative Pain Management, Uniformed Services University of the Health Sciences, Bethesda, MD, USA

5 Henry M Jackson Foundation for the Advancement of Military Medicine, Rockville, MD, USA

6 Department of Medicine, Walter Reed National Military Medical Center, Bethesda, MD, USA

7 University of New Mexico Sleep Disorders Center, Albuquerque, NM, USA

8 Department of Pediatrics, Uniformed Services University of the Health Sciences, Bethesda, MD, USA 
locations and has placed the USA in a public health emergency as the trajectory of cases continues to rise $[5,6]$.

The Federal Drug Administration (FDA) has provided emergency guidance during the crisis caused by the COVID-19 pandemic in an effort to increase immediate access to ventilators, with special mention regarding potential utilization of devices typically used for treatment of obstructive sleep apnea at home, to include noninvasive positive pressure ventilation (NIPPV) devices such as continuous positive airway pressure (CPAP) and bilevel positive airway pressure (bilevel PAP) [5]. The FDA also cautioned that design modifications are to minimize the risk of aerosolization, as SARSCoV-2 has demonstrated viability in the aerosolized form for up to $3 \mathrm{~h}$, and thus poses a risk for infection to health care workers [5, 7]. Unlike conventional mechanical ventilators, home NIPPV devices use a single limb passive breathing circuit with a calibrated intentional leak incorporated into the system, usually on the mask itself, to prevent rebreathing [8]. The intentional leak design of NIPPV devices could potentially lead to aerosolization of the virus and expose healthcare workers to pathogens [9]. Even with a non-vented mask and a bacterial/viral filter placed on an expiratory port to mitigate this, unintentional leak may still occur in the patientmask interface. Therefore, guidelines have cautioned against using traditional NIPPV modalities with a face mask on critically ill patients with COVID-19 [10].

Bilevel PAP devices with back-up respiratory rates [spontaneous/timed mode (ST)] are commonly used at home to treat many conditions including obstructive sleep apnea, and chronic respiratory failure secondary to chronic obstructive pulmonary disease, obesity hypoventilation syndrome, and neuromuscular disease [11-14]. These devices are only approved for NIPPV with the use of a mask interface, and their use for invasive ventilation has not been reported except by one small study [15].

The impending predicted shortage of mechanical ventilators lead us to investigate whether or not bilevel PAP ST devices, designed for noninvasive use at home and the sleep laboratory, could provide invasive ventilation. The objective of this study was to demonstrate the feasibility and effectiveness of using bilevel PAP ST with a single limb filtered respiratory circuit to maintain adequate ventilation and oxygenation in an intubated healthy swine model.

\section{Materials and methods}

\section{Respiratory circuit concept and design}

We designed two single limb respiratory circuits using resources commonly available in a sleep laboratory and respiratory therapy department, with proximal and distal filtration to prevent aerosolization of the virus. The circuits differed in regard to the type of passive exhalation valve used to prevent $\mathrm{CO}_{2}$ retention and rebreathing. The first circuit (see Fig. 1) includes in order of connectivity from device to patient: one bacterial/viral filter (Teleflex Inc., Wayne, Pennsylvania, USA), 6-ft corrugated tubing, one Hudson RCI Pressure Line Adapter (Teleflex Inc., Wayne, Pennsylvania, USA) for an oxygen $\left(\mathrm{O}_{2}\right)$ supply port, an exhaust collector and positive end-expiratory pressure (PEEP) valve (Smith Medical, London, UK), and a second bacterial/viral filter (Teleflex Inc., Wayne, Pennsylvania, USA), which then connects to the endotracheal tube.

The second circuit (see Fig. 2) includes in order of connectivity from device to patient: one bacterial/viral filter (Teleflex Inc., Wayne, Pennsylvania, USA), 6-ft corrugated tubing, a SyncVent@ passive exhalation adaptor (Dräger Medical, Lübeck, Germany), one Hudson RCI Pressure Line Adapter (Teleflex Inc., Wayne, Pennsylvania, USA) for $\mathrm{O}_{2}$ supply port, and a second bacterial/viral filter (Teleflex Inc., Wayne, Pennsylvania, USA), which then connects to the endotracheal tube.

\section{Test lung}

These proof-of-concept circuits were originally tested on a $1 \mathrm{~L}$ test-lung using two commercially available bilevel PAP ST devices designed for NIPPV in the home and sleep laboratory settings. These devices produce an inspiratory positive airway pressure (IPAP) and expiratory positive airway pressure (EPAP), with a timed back-up respiratory rate (RR). Both circuits and devices generated consistent and regular delivery of pressures to the test lung.

\section{Animal preparation and testing}

The Institutional Animal Care and Use Committee at the Uniformed Service University of the Health Sciences approved the animal protocol. Four Yorkshire-cross swine (Sus scrofa domesticus), 63-99 kg, were sedated with tiletamine $(6 \mathrm{mg} / \mathrm{kg})$ intramuscularly to allow ear vein cannulation. Following isoflurane induction and endotracheal intubation, surgical anesthesia was initially provided with isoflurane 1$2 \%$ in $50 \% \mathrm{O}_{2}$. During ventilator testing, anesthesia was transitioned to total intravenous anesthesia by continuous infusion of propofol $2-4.4 \mathrm{mg} / \mathrm{kg} / \mathrm{h}$, combined with midazolam $1-4 \mathrm{mg} / \mathrm{kg} / \mathrm{h}$ and vecuronium $0.1 \mathrm{mg} / \mathrm{kg}$.

The Apollo® anesthesia workstation (Dräger Medical, Lübeck, Germany) is a full feature anesthesia workstation and E-Vent plus servo controlled high-speed piston ventilator. The animals were mechanically ventilated with this machine in the supine position while establishing venous access. Assist control $(\mathrm{A} / \mathrm{C})$ volume ventilation was adjusted to achieve a tidal volume $\left(\mathrm{V}_{\mathrm{T}}\right)$ of $6-10 \mathrm{ml} / \mathrm{kg}$ measured body weight; PEEP $5 \mathrm{~cm} \mathrm{H}_{2} \mathrm{O}$ was applied, and $\mathrm{RR}$ was adjusted to achieve 
Fig. 1 This schematic identifies the connection of the first single limb respiratory circuit tested. 1 . Bilevel PAP ST device. 2. Bacterial/viral filter (Teleflex Inc., part \#1605). 3. 6-ft corrugated tubing. 4. Pressure line adapter (Teleflex Inc., part \#1642). 5. Exhaust collector and positive end expiratory pressure valve (Smith Medical, part \#122002). 6. Bacterial/viral filter (Teleflex Inc., part \#1605). 7. Endotracheal tube

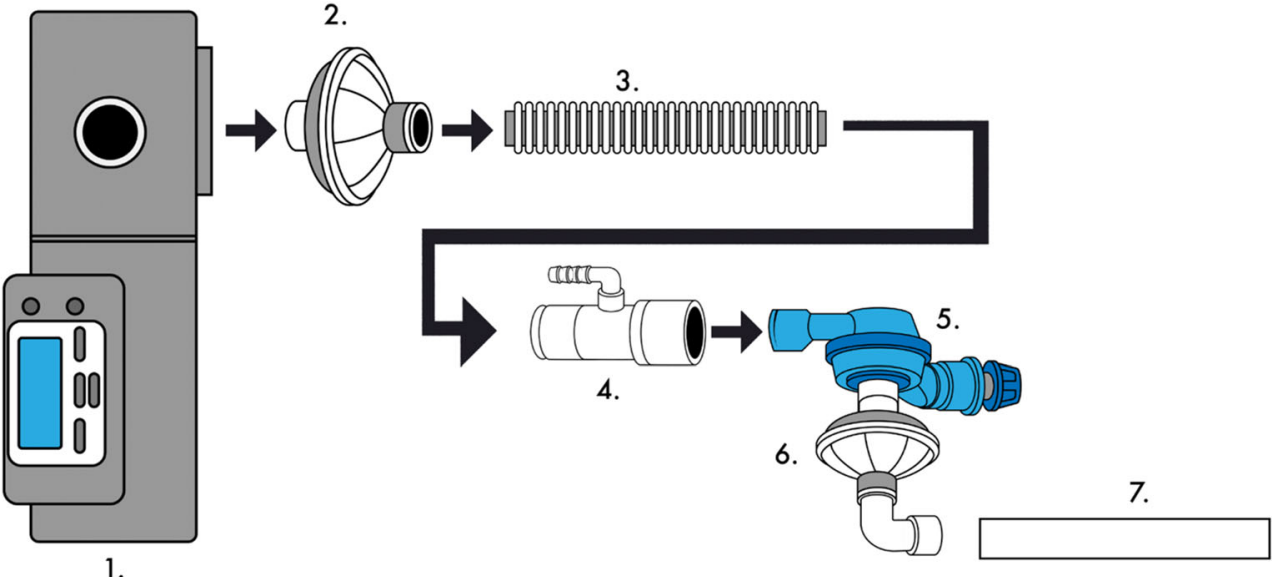

an end-tidal $\mathrm{CO}_{2}\left(\mathrm{ETCO}_{2}\right)$ of $40 \mathrm{mmHg}$ during instrumentation. Isotonic sodium chloride solution was administered at a rate of $500 \mathrm{ml} / \mathrm{h}$ to overcome insensible losses. An underbody warmer was set at $39{ }^{\circ} \mathrm{C}$ and adjusted as needed to maintain body temperature $\left(36.7-39.1^{\circ} \mathrm{C}\right)$.

\section{Physiological measurements}

A $20 \mathrm{~g}$ femoral artery catheter (Cook Medical, Inc., Bloomington, Indiana, USA) was placed percutaneously for blood pressure measurement and arterial blood gas (ABG) sampling. A secondary venous catheter was placed percutaneously in the right hind leg for fluid and drug administration. Solid-state pressure transducer catheters (Transonic Systems Inc., Ithaca, New York, USA) were placed in the esophagus to continuously measure esophageal pressure $\left(\mathrm{P}_{\mathrm{eso}}\right)$ as a surrogate for pleural pressure and through the endotracheal tube into the trachea to measure peak airway pressure.

$\mathrm{V}_{\mathrm{T}}$ and flow-volume loops were monitored continuously with an in-line $1 \mathrm{~L} / \mathrm{min}$ flowhead spirometer (ADInstruments Inc. Colorado Springs, Colorado, USA). Arterial blood pressure (ABP), $\mathrm{P}_{\mathrm{eso}}$, airway pressure, $\mathrm{RR}$, heart rate, fraction of inspired $\mathrm{O}_{2}\left(\mathrm{FiO}_{2}\right)$, and exhaled $\mathrm{ETCO}_{2}$ concentrations were continuously monitored and digitally recorded using
Powerlab data acquisition system (ADInstruments Inc., Colorado Springs, Colorado, USA). ABGs were obtained 20 min following each ventilator change and were analyzed with an i-STAT® Handheld Blood Analyzer (Abbott Point of Care Inc., Princeton, New Jersey, USA). All physiologic parameters were measured at baseline after a 20 -min stabilization period and $20 \mathrm{~min}$ after each experimental condition.

\section{Bilevel PAP ST devices}

The first bilevel PAP ST device (device 1), an OMNILab Advanced + ( (Phillips Respironics, Murrysville, Pennsylvania, USA), has multiple modes designed for sleep laboratory use. This device offers enhanced features designed to perform sleep laboratory titration studies with several advanced modes. For this study, the bilevel PAP ST mode was utilized, which has pressure ranges EPAP 4 to $25 \mathrm{~cm} \mathrm{H}_{2} \mathrm{O}$ and IPAP 4 to $30 \mathrm{~cm} \mathrm{H}_{2} \mathrm{O}$, and RR 0-30 breaths/min. The second bilevel PAP ST (device 2), a RemStar BiPAP S/T® (Philips Respironics, Murrysville, Pennsylvania, USA), is designed for home use. It provides bilevel PAP ST also with EPAP 4 to $25 \mathrm{~cm} \mathrm{H}_{2} \mathrm{O}$ and IPAP 4 to $30 \mathrm{~cm} \mathrm{H}_{2} \mathrm{O}$ and RR $0-30$ breaths/ min. The inspiratory time was set at $1 \mathrm{~s}$ with rise time of 3 for both devices.

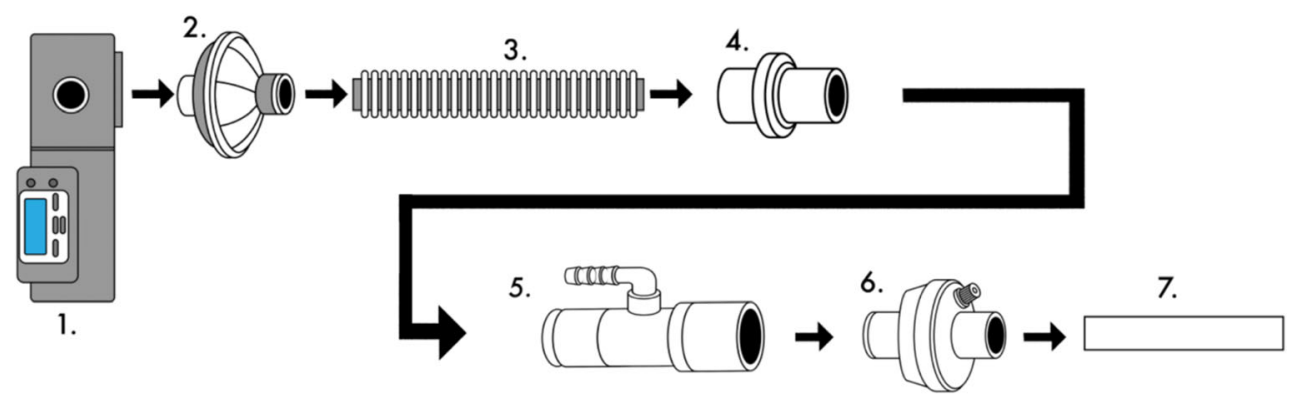

Fig. 2 This schematic identifies the connection of the second single limb respiratory circuit tested. 1. Bilevel PAP ST. 2. Bacterial/viral filter (Teleflex Inc., part \#1605). 3. 6-ft corrugated tubing. 4. Leakage valve for Carina SyncVent (Dräger Medical, part \#MP00224). 5. Pressure line adapter (Teleflex Inc., part \#1642). 6. Bacterial/viral filter (Teleflex Inc., part \#1605). 7. Endotracheal tube 


\section{Experimental protocol}

On preliminary testing, there was no difference in the performance observed between the two single limb respiratory circuits in the animal model, and the second circuit (see Fig. 2) was chosen for the full testing protocol due to its simpler design. Following baseline data acquisition, each device was tested sequentially to characterize the in vivo respiratory mechanics of the two bilevel PAP ST devices as well as the anesthesia ventilator. Each device was set at various IPAP pressures ranging from 15 to $30 \mathrm{~cm} \mathrm{H}_{2} \mathrm{O}$ with various EPAP settings $\left(5,10,15,20 \mathrm{~cm} \mathrm{H}_{2} \mathrm{O}\right)$ and a $\mathrm{RR}$ of 20 breaths/min. Initially and prior to each change in EPAP, a recruitment breath was delivered to recruit as many alveoli as possible. At the end of the recruitment breath, the devices were transitioned to the next higher EPAP setting. At each setting, flow-volume loops, peak airway pressures, mean airway pressures, and compliance data were acquired.

Following characterization of respiratory mechanics, the ability of the bilevel PAP ST devices to deliver a specified minute ventilation $\left(\mathrm{V}_{\mathrm{E}}\right)$ was evaluated. The IPAP/EPAP was adjusted to achieve a $V_{T}$ of $6 \mathrm{ml} / \mathrm{kg}$. The devices were subjected to three scenarios based on different $V_{E}$ levels resulting in respiratory acidosis, normocapnia, and respiratory alkalosis.

\section{Results}

Both bilevel PAP ST devices were tested to characterize the respiratory mechanics at varying IPAP and EPAP levels (see Table 1). When compared to an anesthesia ventilator, both tested devices generated lower $\mathrm{V}_{\mathrm{T}}$ at various settings. Device 1 approximated $V_{T}$ closer to the anesthesia ventilator than device 2. Device 1 provided a slightly higher measured $\mathrm{V}_{\mathrm{T}}$ compared to the anesthesia ventilator only at the IPAP/ EPAP $30 / 20 \mathrm{~cm} \mathrm{H}_{2} \mathrm{O}$ setting. Measured peak inspiratory and expiratory flow rates were generally equal and consistent at equivalent IPAP/EPAP levels. Using $5 \mathrm{~L} / \mathrm{min}$ and $10 \mathrm{~L} / \mathrm{min}$ of oxygen, a $\mathrm{FiO}_{2}$ of 0.50 and 0.85 , respectively, were achieved using the pressure line adaptor in the single limb respiratory circuit.

In the evaluation of the $V_{E}$, the test devices' pressure settings and RR were manipulated targeting a $\mathrm{V}_{\mathrm{T}}$ of $6 \mathrm{ml} / \mathrm{kg}$ to generate three acid-base balance conditions: respiratory acidosis, normocapnia, and respiratory alkalosis. These scenarios were performed in three separate trials, one using device 1 and two using device 2 (see Table 2).

In trial 1 , device 1 was programmed to deliver an IPAP of $23 \mathrm{~cm} \mathrm{H}_{2} \mathrm{O}$ and an EPAP of $10 \mathrm{~cm} \mathrm{H}_{2} \mathrm{O}$. These pressures were maintained throughout all three scenarios. To induce respiratory acidosis, the RR was programmed to 10 breaths/min and an $\mathrm{ABG}$ revealed respiratory acidosis, with $\mathrm{pH}$ 7.31, and
$\mathrm{PaCO}_{2}$ of $61.9 \mathrm{mmHg}$ with $\mathrm{ETCO}_{2}$ of $65 \mathrm{mmHg}$. Next, the RR was increased to $20 \mathrm{breath} / \mathrm{min}$ in an effort to reach eucapnia. $\mathrm{ABG}$ revealed a $\mathrm{pH} 7.43$, and a $\mathrm{PaCO}_{2} 45 \mathrm{mmHg}$ with $\mathrm{ETCO}_{2}$ at $43 \mathrm{mmHg}$. Next, the RR was increased to 25 breaths/min to induce respiratory alkalosis, and an $\mathrm{ABG}$ revealed a $\mathrm{pH} 7.45$, and a $\mathrm{PaCO}_{2} 44.7 \mathrm{mmHg}$ with $\mathrm{ETCO}_{2}$ $38 \mathrm{mmHg}$.

In trial 2, device 2 was programmed to deliver an IPAP of $20 \mathrm{~cm} \mathrm{H}_{2} \mathrm{O}$ and an EPAP of $10 \mathrm{~cm} \mathrm{H}_{2} \mathrm{O}$. To induce respiratory acidosis, the RR was programmed to 15 breaths $/ \mathrm{min}$ and an ABG was obtained. This caused a respiratory acidosis with a pH 7.38, and $\mathrm{PaCO}_{2} 51.9 \mathrm{mmHg}$ with $\mathrm{ETCO}_{2} 51 \mathrm{mmHg}$. Next, the IPAP was decreased to $18 \mathrm{~cm} \mathrm{H}_{2} \mathrm{O}$ and the RR was increased to 20 breaths/min in an effort to reach eucapnia. An ABG revealed a pH 7.41, and a $\mathrm{PaCO}_{2} 47.9 \mathrm{mmHg}$ with $\mathrm{ETCO}_{2} 51 \mathrm{mmHg}$. Next, the IPAP was increased to $25 \mathrm{~cm}$ $\mathrm{H}_{2} \mathrm{O}$ and the $\mathrm{RR}$ was increased to 30 breaths/min to induce respiratory alkalosis, and an $\mathrm{ABG}$ revealed a $\mathrm{pH}$ 7.53, and a $\mathrm{PaCO}_{2} 34.9 \mathrm{mmHg}$ with an $\mathrm{ETCO}_{2} 30 \mathrm{mmHg}$.

In trial 3, device 2 was programmed to deliver an IPAP of $23 \mathrm{~cm} \mathrm{H}_{2} \mathrm{O}$ and an EPAP of $10 \mathrm{~cm} \mathrm{H}_{2} \mathrm{O}$. To induce respiratory acidosis, the RR was programmed to 10 breaths/min and an ABG revealed a respiratory acidosis with a $\mathrm{pH} 7.35$, and a $\mathrm{PaCO}_{2}$ of $55.1 \mathrm{mmHg}$ with $\mathrm{ETCO}_{2} 55 \mathrm{mmHg}$. Next, the RR was increased to $20 \mathrm{breath} / \mathrm{min}$ in an effort to reach eucapnia. An ABG revealed a pH 7.43 and a $\mathrm{PaCO}_{2} 44.8 \mathrm{mmHg}$ with $\mathrm{ETCO}_{2} 44 \mathrm{mmHg}$. Next, the IPAP was increased to $25 \mathrm{~cm}$ $\mathrm{H}_{2} \mathrm{O}$ and the RR was increased to 22 breaths/min to induce respiratory alkalosis, and an $\mathrm{ABG}$ revealed a $\mathrm{pH} 7.45$ and a $\mathrm{PaCO}_{2} 42.4 \mathrm{mmHg}$ with an $\mathrm{ETCO}_{2} 42 \mathrm{mmHg}$.

\section{Discussion}

In the current study, we demonstrated the feasibility of noninvasive home and sleep laboratory bilevel PAP ST devices to provide invasive ventilation with two different single limb passive breathing circuits with an intentional leak. These devices were able to maintain both adequate ventilation and oxygenation. Furthermore, both devices were able to induce respiratory alkalosis. This is the first study using an animal model to evaluate the ability of NIPPV home and sleep laboratory devices to provide invasive ventilation in the context of the current COVID-19 pandemic.

Mechanical ventilators are complex and expensive medical devices that require specialized training for safe and effective use. Positive pressure is delivered via a respiratory circuit that connects ventilator tubing to either an endotracheal tube or a noninvasive mask interface. Most conventional mechanical ventilators use a double-limb respiratory circuit, composed of inspiratory and expiratory limbs. The limbs attach to a ventilator and contain one-way valves that prevent rebreathing and $\mathrm{CO}_{2}$ retention. These limbs meet at 
Table 1 Comparison of respiratory mechanics of the bilevel PAP ST devices and the anesthesia ventilator

\begin{tabular}{|c|c|c|c|}
\hline Variables & Device 1 & Device 2 & Anesthesia ventilator $^{\mathrm{a}}$ \\
\hline \multicolumn{4}{|c|}{ IPAP/EPAP 15/5 (cm H2O); RR 20 (breaths/min) } \\
\hline Measured VT (ml) & 377 & 306 & 416 \\
\hline Measured PIP/PEEP $\left(\mathrm{cm} \mathrm{H}_{2} \mathrm{O}\right)$ & $15 / 6.5$ & $13 / 7$ & $15 / 7$ \\
\hline Measured PIF (L/s) & 0.44 & 0.37 & 0.39 \\
\hline Measured PEF (L/s) & 0.37 & 0.31 & 0.37 \\
\hline $\mathrm{Ti}(\mathrm{s})$ & 1.09 & 1.04 & 1.43 \\
\hline \multicolumn{4}{|c|}{ IPAP/EPAP 20/10 ( $\left.\mathrm{cm} \mathrm{H}_{2} \mathrm{O}\right)$; RR 20 (breaths/min) } \\
\hline Measured VT $(\mathrm{ml})$ & 365 & 307 & 420 \\
\hline Measured PIP/PEEP (cm H2O) & $20 / 12$ & $18 / 12$ & $18 / 12$ \\
\hline Measured PIF (L/s) & 0.44 & 0.39 & 0.41 \\
\hline Measured PEF (L/s) & 0.34 & 0.31 & 0.39 \\
\hline $\mathrm{Ti}(\mathrm{s})$ & 1.07 & 1.06 & 1.06 \\
\hline \multicolumn{4}{|c|}{ IPAP/EPAP 23/10 (cm H $\left.\mathrm{H}_{2} \mathrm{O}\right)$; RR 20 (breaths/min) } \\
\hline Measured VT (ml) & 441 & 371 & 460 \\
\hline Measured PIP/PEEP $\left(\mathrm{cm} \mathrm{H}_{2} \mathrm{O}\right)$ & $20.5 / 11$ & $20.5 / 10.5$ & $23 / 13$ \\
\hline Measured PIF (L/s) & 0.51 & 0.47 & 0.49 \\
\hline Measured PEF (L/s) & 0.40 & 0.34 & 0.42 \\
\hline $\mathrm{Ti}(\mathrm{s})$ & 1.08 & 1.05 & 1.31 \\
\hline \multicolumn{4}{|c|}{ IPAP/EPAP 30/15 ( $\left.\mathrm{cm} \mathrm{H}_{2} \mathrm{O}\right)$; RR 20 (breaths/min) } \\
\hline Measured VT (ml) & 474 & 396 & 500 \\
\hline Measured PIP/PEEP $\left(\mathrm{cm} \mathrm{H}_{2} \mathrm{O}\right)$ & $30 / 17$ & $28 / 17$ & $31 / 18$ \\
\hline Measured PIF (L/s) & 0.59 & 0.51 & 0.55 \\
\hline Measured PEF (L/s) & 0.45 & 0.38 & 0.5 \\
\hline $\mathrm{Ti}(\mathrm{s})$ & 1.06 & 1.04 & 1.30 \\
\hline \multicolumn{4}{|c|}{ IPAP/EPAP 30/20 (cm H $2 \mathrm{O}) ;$ RR 20 (breaths/min) } \\
\hline Measured VT (ml) & 300 & 252 & 269 \\
\hline Measured PIP/PEEP (cm H2O) & $31 / 21$ & $29 / 21$ & $30.5 / 22$ \\
\hline Measured PIF (L/s) & 0.44 & 0.42 & 0.42 \\
\hline Measured PEF (L/s) & 0.38 & 0.35 & 0.33 \\
\hline $\mathrm{Ti}(\mathrm{s})$ & 1.05 & 1.04 & 1.10 \\
\hline
\end{tabular}

$I P A P$ inspiratory positive airway pressure, $E P A P$ expiratory positive airway pressure, $R R$ respiratory rate, $V_{T}$ tidal volume, $P I P$ peak inspiratory pressure, $P E E P$ peak end expiratory pressure, $P I F$ peak inspiratory flow, $P E F$ peak expiratory flow, $T i$ inspiratory time

${ }^{\text {a }}$ Using standard dual limb respiratory circuit in pressure control mode a Y-connector distally that then connects to an endotracheal tube. Humidification and filtration can be connected within the circuit at various locations $[8,16]$. A critical shortage of medical resources is projected during the COVID-19 pandemic [6]. When ventilators are unavailable, bilevel PAP ST devices could be used with endotracheal intubation, but it must be understood that they were not approved to be used in this way and would be used under a special FDA exception during this crisis situation [5].

One potential concern for using bilevel PAP ST devices invasively is that these devices were not designed to overcome the resistance of an endotracheal tube. In this study, we found that the intratracheal pressures were fairly consistent with the use of the bilevel PAP ST devices and were comparable to those obtained with an anesthesia ventilator, so the added resistance of an endotracheal tube compared to a mask interface did not affect significantly the functionality of these devices. There was also concern that the $\mathrm{FiO}_{2}$ that could be achieved with bleed-in $\mathrm{O}_{2}$ adaptors would be severely limited. However, the bilevel PAP ST devices were able to maintain a $\mathrm{FiO}_{2}$ of 0.5 and 0.85 with an $\mathrm{O}_{2}$ bleed-in rate of $5 \mathrm{~L} / \mathrm{min}$ and $10 \mathrm{~L} / \mathrm{min}$, respectively, and thus, oxygenation does not appear to be a severe limitation of these circuits and devices.

Interestingly, device 1 achieved higher $\mathrm{V}_{\mathrm{T}}$ than device 2 at various pressure settings. Device 1 is a newer, multi-function device designed for sleep laboratories, and device 2 is a simpler bilevel PAP ST designed for home use. In the $\mathrm{V}_{\mathrm{E}}$ challenge, tachypnea was needed to achieve eucapnia. This is 
Table 2 Bilevel PAP ST device trials with data to assess control of minute ventilation

\begin{tabular}{|c|c|c|c|}
\hline & Hypoventilation & Normal ventilation & Hyperventilation \\
\hline \multicolumn{4}{|l|}{ Trial 1} \\
\hline Prescribed IPAP/EPAP $\left(\mathrm{cm} \mathrm{H}_{2} \mathrm{O}\right)$ & $23 / 10$ & $23 / 10$ & $23 / 10$ \\
\hline RR (breaths/min) & 10 & 20 & 25 \\
\hline Measured PIP/PEEP $\left(\mathrm{cm} \mathrm{H}_{2} \mathrm{O}\right)$ & $24 / 10$ & $22.5 / 10$ & $20 / 8.5$ \\
\hline $\mathrm{pH}$ & 7.31 & 7.43 & 7.45 \\
\hline $\mathrm{PaCO}_{2}(\mathrm{mmHg})$ & 61.9 & 45.0 & 44.7 \\
\hline $\mathrm{ETCO}_{2}(\mathrm{mmHg})$ & 65 & 43 & 38 \\
\hline \multicolumn{4}{|l|}{ Trial 2} \\
\hline Prescribed IPAP/EPAP $\left(\mathrm{cm} \mathrm{H}_{2} \mathrm{O}\right)$ & $20 / 10$ & $18 / 10$ & $25 / 10$ \\
\hline RR (breaths/min) & 15 & 20 & 30 \\
\hline Measured PIP/PEEP $\left(\mathrm{cm} \mathrm{H}_{2} \mathrm{O}\right)$ & $17 / 10$ & $16 / 10$ & $22 / 12$ \\
\hline $\mathrm{pH}$ & 7.38 & 7.41 & 7.53 \\
\hline $\mathrm{PaCO}_{2}(\mathrm{mmHg})$ & 51.9 & 47.9 & 34.9 \\
\hline $\mathrm{ETCO}_{2}(\mathrm{mmHg})$ & 51 & 51 & 30 \\
\hline \multicolumn{4}{|l|}{ Trial 3} \\
\hline Prescribed IPAP/EPAP $\left(\mathrm{cm} \mathrm{H}_{2} \mathrm{O}\right)$ & $23 / 10$ & $23 / 10$ & $25 / 10$ \\
\hline RR (breaths/min) & 10 & 20 & 22 \\
\hline Measured PIP/PEEP $\left(\mathrm{cm} \mathrm{H}_{2} \mathrm{O}\right)$ & $22 / 12$ & $22 / 10$ & $21 / 7.5$ \\
\hline $\mathrm{pH}$ & 7.35 & 7.43 & 7.45 \\
\hline $\mathrm{PaCO}_{2}(\mathrm{mmHg})$ & 55.1 & 44.8 & 42.4 \\
\hline $\mathrm{ETCO}_{2}(\mathrm{mmHg})$ & 55 & 44 & 42 \\
\hline
\end{tabular}

Trial 1 was performed using device 1 . Trials 2 and 3 were performed using device 2

$I P A P$ inspiratory positive airway pressure, $E P A P$ expiratory positive airway pressure, $R R$ respiratory rate, $P I P$ peak inspiratory pressure, $P E E P$ peak end expiratory pressure clinically relevant, as higher RRs may be required to maintain adequate $\mathrm{V}_{\mathrm{E}}$, and as we identified, different devices may perform differently at the same pressure and rate settings.

Because these devices would only be considered for invasive use in resource-constrained situations, there is an implication that during use, one or more parts of the respiratory circuit will be unavailable. The single limb circuits used in this study were constructed from parts that are usually readily available commercially and were not especially manufactured for the study. Potentially, adequate replacements for the circuit components could be rapidly manufactured as needed. Both tested circuits performed well, but we felt that the SyncVent passive exhalation adapter was simpler to use. The exhaust collector and PEEP valve assembly had to be adjusted with changes in the EPAP setting, whereas the SyncVent passive exhalation adapter did not need any additional adjustments.

To our knowledge, only one study has reported the use of a bilevel PAP ST device designed exclusively for NIPPV for invasive ventilation. In an observational study performed in India, 20 patients with COPD exacerbation and reduced level of consciousness, who could not afford the use of a standard mechanical ventilator, were intubated and placed on a bilevel PAP ST (BiPAP S/T) [15]. Therapy was successful in $85 \%$ of the patients, defined as gaining full consciousness and being discharged home. All responders had improvement at $2 \mathrm{~h}$ of therapy, compared to the non-responders, who did not. The duration of ventilation for responders was 3.8 (2.7 to 5.0) days, while length of hospitalization was 8 (5 to 15$)$ days.

A similar study was conducted in Pakistan with endotracheal intubation utilizing a Stellar 150 device (ResMed, San Diego, California, USA) (personal communication, author), a more advanced device compared to a bilevel PAP ST [17]. This device is approved for noninvasive and invasive use at home and in healthcare settings. This study described 44 consecutive patients with severe COPD exacerbation with reduced level of consciousness. Thirty-one (70.5\%) patients responded to therapy. All responders had improvement at $2 \mathrm{~h}$ of therapy, compared to the non-responders, who did not [17].

While bilevel PAP ST devices cannot generate peak pressures higher than $30 \mathrm{~cm} \mathrm{H}_{2} \mathrm{O}$, they appear to be capable of maintaining and manipulating $\mathrm{V}_{\mathrm{E}}$ in this model. These devices could be used to ventilate patients invasively prior to the onset of severe ARDS. It is worth noting that hypoxemic respiratory failure associated with COVID-19 is a heterogeneous process [18]. Therefore, it may be premature to dismiss using NIPPV devices generating lower pressures as there may be a greater role for these devices as our understanding of COVID-19 
physiology evolves. Unusually, long periods of ventilation in COVID-19 patients have been reported, and bilevel PAP ST devices could also be utilized invasively in a post-ARDS setting when attempting to wean from the ventilator to allow conventional ventilators to be allocated to more severe and critically ill ARDS cases [19].

Other single limb circuit designs could potentially be used other than the ones that we tested. If required in a resourcepoor condition, the key principles to consider when constructing these circuits are that all exhaled air must be filtered and the exhalation port or valve leak must be adequate to prevent rebreathing of $\mathrm{CO}_{2}$.

This was a proof-of-concept design that was intended to show the feasibility of using bilevel PAP ST devices for invasive ventilation in an animal model. There are limitations to both this study design and to the practical application. Regarding the study design limitations, we used a healthy swine model. It is unknown if the performance of the bilevel PAP ST devices would be comparable in a swine model or human with ARDS, which limits the generalizability of these findings. A future study of bilevel PAP ST in a diseased/ ARDS model is warranted.

There are four important limitations to the practical application that clinicians should consider when using bilevel PAP ST devices as standard ventilators. First, these devices do not usually have an internal battery, and an uninterrupted power supply is recommended as back-up. Second, they are not meant for continuous uninterrupted use. It is not well known how the devices will perform when used continuously for many days or how long they will function without needing replacement when used under those conditions. Third, alarms are usually not included on these devices, requiring closer monitoring of these patients. Use of continuous pulse oximetry, telemetry, $\mathrm{ETCO}_{2}$ monitoring, and airway pressure monitoring would provide an extra layer of safety. A flow sensor in the circuit, adjacent to the patient, could provide a source for an alarm. Fourth, $\mathrm{V}_{\mathrm{T}}$ cannot be measured directly, unlike conventional mechanical ventilators, unless an external measuring device is used.

The proposed circuit has shown feasibility in an animal model and may be considered as an alternative method of providing adequate ventilation and oxygenation if all conventional ventilator options have been exhausted. Further studies in animal models of ARDS and in humans would provide more information of the utility of these devices in the current COVID-19 pandemic and beyond. Given the FDA emergency use authorization and the scarcity of ventilator options during the COVID-19 pandemic, we felt it necessary to provide these early findings to the medical community.

Acknowledgments The authors would like to acknowledge Drs. Robert Browning, Christian Popa, and Jacob Collen for their review and assistance with this article. The authors would also like to acknowledge Luke Martin for his artistic contributions in Figs. 1 and 2.
Disclaimer The identification of specific products or scientific instrumentation is considered an integral part of the scientific endeavor and does not constitute endorsement or implied endorsement on the part of the author, Department of Defense, or any component agency. The views expressed in this article are those of the author(s) and do not reflect the official policy of the Department of Army/Navy/Air Force, Department of Defense, or U.S. Government.

Author contributions Dr. Foster provided initial concept, design, and construction of both single limb respiratory circuits, completed initial evaluation of the bilevel PAP ST devices, coordinated testing, analyzed the collected data, and prepared the manuscript. Dr. Diaz-Abad provided background review, analyzed the collected data, and prepared the manuscript. Drs. Hudson and Bedocs performed the evaluation of the devices, collected data, provided data analysis, and contributed to manuscript writing. Mr. Doll and Mr. Lopez assisted with design and construction of the single limb respiratory circuits and provided practical ventilator experience. Mr. Mares and Mr. Hutzler conducted the animal testing protocol and provided veterinary services. Dr. Robertson (guarantor of project) initiated the project, coordinated testing, analyzed the collected data, prepared the manuscript, and oversaw all project contributions. All authors reviewed and approved of the final manuscript.

Funding This study was funded by U.S. Department of Defense Joint Acquisition Task Force (SUR-90-10378).

\section{Compliance with ethical standards}

Conflict of interest All authors declare they did not have financial support for this research. All authors do not have any financial interests, or connections, direct or indirect, or other situations that might raise the question of bias in this manuscript or the conclusions, implications, or opinions stated - including pertinent commercial or other sources of funding for the individual authors or for the associated departments or organizations, personal relationships, or direct academic competition for each author.

Ethical approval The Institutional Animal Care and Use Committee at the Uniformed Service University of the Health Sciences approved the animal protocol. All applicable international, national, and/or institutional guidelines for the care and use of animals were followed. This article does not contain any studies with human participants performed by any of the authors.

\section{References}

1. Fauci AS, Lane HC, Redfield RR (2020) Covid-19 — navigating the uncharted. N Engl J Med 382(13):1268-1269

2. Li Q, Guan X, Wu P, Wang X, Zhou L, Tong Y, Ren R, Leung KSM, Lau EHY, Wong JY, Xing X, Xiang N, Wu Y, Li C, Chen Q, Li D, Liu T, Zhao J, Liu M, Tu W, Chen C, Jin L, Yang R, Wang Q, Zhou S, Wang R, Liu H, Luo Y, Liu Y, Shao G, Li H, Tao Z, Yang Y, Deng Z, Liu B, Ma Z, Zhang Y, Shi G, Lam TTY, Wu JT, Gao GF, Cowling BJ, Yang B, Leung GM, Feng Z (2020) Early transmission dynamics in Wuhan, China, of novel coronavirus-infected pneumonia. N Engl J Med 382(13):1199-1207

3. Du Y, Tu L, Zhu P, Mu M, Wang R, Yang P, et al. Clinical features of 85 fatal cases of COVID-19 from Wuhan: a retrospective observational study. Am J Respir Crit Care Med.0(ja):null

4. Organization WH. Coronavirus disease (COVID-19) outbreak. URL https://www.who.int/emergencies/diseases/novelcoronavirus-2019 Accessed March. 2020 
5. FDA. Enforcement Policy for Ventilators and Accessories and Other Respiratory Devices During the Coronavirus Disease 2019 (COVID-19) Public Health Emergency. Guidance for Industry and Food and Drug Administration Staff. In: Office of Medical Products and Tobacco CfDaRH, editor. 2020

6. Koonin LM, Pillai S, Kahn EB, Moulia D, Patel A (2020) Strategies to inform allocation of stockpiled ventilators to healthcare facilities during a pandemic. Health Secur

7. van Doremalen N, Bushmaker T, Morris DH, Holbrook MG, Gamble A, Williamson BN et al (2020) Aerosol and surface stability of SARS-CoV-2 as compared with SARS-CoV-1. N Engl J Med

8. Gregoretti C, Navalesi P, Ghannadian S, Carlucci A, Pelosi P (2013) Choosing a ventilator for home mechanical ventilation. Breathe. 9(5):394-409

9. Simonds AK, Hanak A, Chatwin M, Morrell M, Hall A, Parker KH et al (2010) Evaluation of droplet dispersion during non-invasive ventilation, oxygen therapy, nebuliser treatment and chest physiotherapy in clinical practice: implications for management of pandemic influenza and other airborne infections. Health Technol Assess 14(46): 131-172

10. Alhazzani W, Møller MH, Arabi YM, Loeb M, Gong MN, Fan E, et al. Surviving sepsis campaign: guidelines on the management of critically ill adults with Coronavirus Disease 2019 (COVID-19). Read Online: Critical Care Medicine | Society of Critical Care Medicine. 9000; Online First

11. Afshar M, Brozek JL, Soghier I, Kakazu MT, Wilson KC, Masa JF, Mokhlesi B (2020) The role of positive airway pressure therapy in adults with obesity hypoventilation syndrome. A systematic review and meta-analysis. Ann Am Thorac Soc 17(3):344-360

12. Guilleminault C, Philip P, Robinson A. Sleep and neuromuscular disease: bilevel positive airway pressure by nasal mask as a treatment for sleep disordered breathing in patients with neuromuscular disease. Journal of Neurology, Neurosurgery \&amp; Psychiatry. 1998;65(2):225-232

13. Ergan B, Oczkowski S, Rochwerg B, Carlucci A, Chatwin M, Clini E, et al. European Respiratory Society guidelines on long-term home non-invasive ventilation for management of COPD. Eur Respir J. 2019;54(3)

14. Gantzhorn EK, Prior TS, Hilberg O (2019) Long-term non-invasive ventilation for stable chronic hypercapnic COPD. Eur Clin Respir J 6(1): 1644893

15. Rawat J, Sindhwani G, Biswas D, Dua R (2012) Role of BiPAP applied through endotracheal tube in unconscious patients suffering from acute exacerbation of COPD: a pilot study. Int J Chron Obstruct Pulmon Dis 7:321-325

16. MacIntyre N (2016) Design features of modern mechanical ventilators. Clin Chest Med 37(4):607-613

17. Akhter N, Rizvi NA (2017) Application of BiPAP through endotracheal tube in comatose patients with COPD exacerbation. Pak J Med Sci 33(6):1444-1448

18. Gattinoni L, Coppola S, Cressoni M, Busana M, Chiumello D (2020) Covid-19 does not Lead to a "typical" acute respiratory distress syndrome. Am J Respir Crit Care Med 201:1299-1300

19. Tian S, Hu N, Lou J, Chen K, Kang X, Xiang Z et al (2020) Characteristics of COVID-19 infection in Beijing. J Inf Secur 80(4):401-406

Publisher's note Springer Nature remains neutral with regard to jurisdictional claims in published maps and institutional affiliations. 